Technical Progress Report Number 1

DOE Contract Number DE-FG22-89PC89768

\title{
PULSED ELECTRON BEAM PRECHARGER
}

For the Period

September 1, 1989 - November 30, 1989

Submitted by

Aerosol Physics Research Group

Department of Physics

The Florida State University

Tallahassee, FL 32306-3016

Principal Investigator

Dr. W. Neil Shelton

Professor of Physics

(904) 644-6552

Report Editor

Wright C. Finney

Associate in Research

(904) 644-2878

DE92 017638 
"US/DOE Patent Clearance is not required prior to the publication of this document."

\section{DISCLAIMER}

This report was prepared as an account of work sponsored by an agency of the United States Government. Neither the United States Government nor any agency thereof, nor any of their employees, makes any warranty, express or implied, or assumes any legal liability or responsibility for the accuracy, completeness, or usefulness of any information, apparatus, product, or process disclosed, or represents that its use would not infringe privately owned rights. Reference herein to any specific commercial product, process, or service by trade name, trademark, manufacturer, or otherwise does not necessarily constitute or imply its endorsement, recommendation, or favoring by the United States Government or any agency thereof. The views and opinions of authors expressed herein do not necessurily state or reflect those of the United States Government or any agency thereof. 
Technical Progress Report No. 1

September 1, 1989 - November 30, 1989

\section{TABLE OF CONTENTS}

Page

A. INTRODUCTION AND SUMMARY . . . . . . . . . . . . . . . . . . . . 1

B. ELECTRON BEAM PRECIPITATOR TEST SYSTEM . . . . . . . . . . . 7

C. CONTRACT PROGRESS DURING QUARTER ONE . . . . . . . . . . . 21

1. TASK A - Precharger Modification . . . . . . . . . . . . . . . . . . . 21

2. TASK B - Installation of Charge-vs.-Radius Apparatus . . . . . . . . . . . . . 21

3. TASK C - Modification and Installation of Pulsed Power Supply . . . . . . . . . 24

4. TASKS D-H - Preparations for Experiments . . . . . . . . . . . . . . . . 27

D. PUBLICATIONS, PRESENTATIONS, AND PARTICIPATIONS . . . . . 31

1. Free Electron Charging of Aerosol Particles - O'Hara et. al. . . . . . . . . . . . 31

2. Flue Gas Cleanup Peer Review Meeting - Bethesda, MD . . . . . . . . . . . . 50

E. PERSONINEL . . . . . . . . . . . . . . . . . . . . . . . . . . . . . . . 51 


\section{Table and Figure Captions}

Table 1. Mk. III Electron Beam Precharging Data.

Figure 1. The FSU Two-Stage Electron Beam Precipitator (EBP) Wind Tunnel.

Figure 2. The Microprocessor-based Data Acquisition and Analysis System serving the Electron Beam Precipitator.

Figure 3. The Precharging Module within the EBP Wind Tunnel.

Figure 4. Schernatic Diagram of the $100 \mathrm{keV}$ Electron Beam Accelerator (MINACC).

Figure 5. Top View of the BG-2 Vacuum Station, the $100 \mathrm{keV}$ Electron Beam Accelerator, and the Mk. III E-Beam Precharging Module.

Figure 6. Top View of the Mk. III-B Electron Beam Precharging Module showing the lonization and Charging Zones.

Figure 7. Detail of the Collecting Module showing the Six Corona Wire and Collector Plate Assemblies.

Figure 8. The FSU Particie Charge vs. Radius (Q/A) Monitoring Apparatus, showing the Laser, Video Recording Syistem, and the Particle Charge Measurement Cell.

Figure 9. Schematic Diagram of the High Voltage Pulse Generating Circuit to be used for E-Beam Pulsed Particle Precharging.

Figure 10. Top View of the High Voltage Pulsed Power Supply showing the Rectifier Network, the Capacitor Bank, and the Rotating Spark Gap.

Figure 11. Schematic Diagram of the Fluidized Bed Aerosol Generator (FBAG) which Resuspends Fly Ash and Hydral Dust. 


\section{A. INTRODUCTION AND SUMMARY}

Work commenced this quarter on the U.S. DOE - PETC contract entitled "Pulsed Electron Beam Precharger," \#DE-FG22-89PC89768, which covers the period September 1, 1989 - August 31, 1991. This is the fifth in a series of contracts and grants exploring the advanced particulate pollution control technology of electron beam precipitation. Technical Progress Report 1 covers the period September 1, 1989 - November 30, 1989, and also includes some work completed during the lapse period between contracts of March - August, 1989.

The chief goal of the current contract is to develop a laboratory scale electron beam precharger using a pulsed electric field to the proof-of-concept stage. Contract tasks leading to the achievement of this goal are generally divided up into two categories: tasks required to bring the Electron Beam Precipitator (EBP) test system up to an operational level for the contract work, and tasks concerning the actual experimental and analytical phase of the study. Not unexpectedly, the early portion of the contract duration will be devoted to the commissioning of the EBP and its many subsystems, while the latter portion will devote itself to testing the new pulsed electron beam precharger.

During the previous contract, a number of important results concerning the E-beam precharging of particles were obtained. Collection efficiencies of up to $99.97 \%$ (Run 3, Table 1) were achieved using fine, high resistivity polystyrene latex (PSL) particles at low concentrations. Improvement in collection efficiency due to the enhancement of particle charge by electron beam precharging is designated by the $\alpha$-value (particle penetration with precharging $\div$ penetration with no precharging). Collection efficiency increases of up to a factor of almost $200(\alpha=190$, efficiency of collector $=94.75 \%$, efficiency of collector and precharger $=99.97 \%)$ were achieved in one case. In another case, an initial collector-only efficiency of $59.9 \%$ was improved to $99.55 \%$ with the addition of precharging. 
Table 1. Mk. III Electron Beam Precharging Data.

\begin{tabular}{|c|c|c|c|c|c|c|c|c|c|c|}
\hline $\begin{array}{l}\text { Experimental } \\
\text { Parameters }\end{array}$ & Run No. & $\begin{array}{l}\text { Precharger } \\
\text { Gas } \\
\text { Velocity } \\
(f t / s t e)\end{array}$ & $\begin{array}{l}\text { Collector } \\
\text { Electric } \\
\text { Field } \\
(\mathrm{kV} / \mathrm{cm})\end{array}$ & $\begin{array}{l}\text { Electron } \\
\text { Beam } \\
\text { Energy } \\
\text { (keV) }\end{array}$ & $\begin{array}{l}\text { Electron } \\
\text { Beam } \\
\text { Current } \\
\quad(\mu \mathrm{A})\end{array}$ & $\begin{array}{l}\text { Prech. } \\
\text { Electric } \\
\text { Field } \\
\text { (kV) }\end{array}$ & $\begin{array}{l}\text { Ion } \\
\text { Current } \\
\text { Density } \\
\left(m A / m^{2}\right)\end{array}$ & $\begin{array}{l}\text { coll. } \\
\text { only } \\
\left(\eta_{1}\right)\end{array}$ & $\begin{array}{l}\text { Prech. } \\
\text { and } \\
\text { coll. } \\
\left(\eta_{2}\right)\end{array}$ & $\alpha=\frac{P_{1}}{P_{2}}$ \\
\hline 1. Wing Plate & 1 & 4.8 & 3.5 & 90 & 2 & 5.1 & 1.51 & 95.55 & 99.95 & 85.6 \\
\hline Electrodes & 2 & 4.8 & 3.5 & 90 & 2 & 5.1 & 1.51 & 94.75 & 99.97 & 190.0 \\
\hline 2. 2 coll. Chan. & 3 & 4.8 & 3.5 & 90 & 2 & 5.1 & 1.51 & 94.75 & 99.97 & 190.0 \\
\hline vs. I coll. Chan. & 4 & 4.8 & 3.5 & 90 & 2 & 5.1 & 1.51 & 78.75 & 99.41 & 36.2 \\
\hline 3. Precharger (104) & 5 & 4.8 & 3.5 & 90 & 2 & 5.1 & 1.08 & 69.4 & 99.17 & 36.8 \\
\hline Gas (43) & 6 & 11.6 & 3.5 & 90 & 2 & 5.1 & 1.08 & 14.6 & 67.60 & 2.63 \\
\hline Velocity (27) & 7 & 18.8 & 3.5 & 90 & 2 & 5.1 & 1.08 & 10.2 & 48.00 & 1.73 \\
\hline 4. Collector & 8 & 4.8 & 3.5 & 90 & 2 & 5.1 & 1.08 & 69.4 & 99.17 & 36.80 \\
\hline Electric Field & 9 & 4.8 & 4.0 & 90 & 2 & 5.1 & 1.08 & 93.6 & 99.67 & 19.30 \\
\hline \multirow{4}{*}{$\begin{array}{l}\text { 5. Electron Beam } \\
\text { Current }\end{array}$} & 10 & 4.8 & 3.5 & 90 & 5 & 5.1 & 1.72 & 65.8 & 96.18 & 8.97 \\
\hline & 11 & 4.8 & 3.5 & 90 & 3 & 5.1 & 1.51 & 65.8 & 98.36 & 20.90 \\
\hline & 12 & 4.8 & 3.5 & 90 & 1 & 5.1 & 1.08 & 65.8 & 99.03 & 35.50 \\
\hline & 13 & 4.8 & 3.5 & 90 & 0.2 & 5.1 & 0.43 & 65.8 & 95.70 & 7.97 \\
\hline \multirow{3}{*}{$\begin{array}{l}\text { 6. Precharger } \\
\text { Ion Current }\end{array}$} & 14 & 4.8 & 3.5 & 90 & 5 & 5.1 & 1.72 & 59.90 & 98.26 & 23.00 \\
\hline & 15 & 4.8 & 3.5 & 90 & 2 & 5.1 & 1.29 & 59.90 & 99.55 & 89.40 \\
\hline & 16 & 4.8 & 3.5 & 90 & 0.5 & 5.1 & 0.65 & 59.90 & 96.73 & 12.30 \\
\hline 7. Precharger & 17 & 4.8 & 3.5 & 90 & 2 & 5.1 & 1.64 & 68.25 & 99.10 & 35.10 \\
\hline Electric & 18 & 4.8 & 3.5 & 90 & 2 & 4.4 & 1.38 & 68.25 & 99.00 & 31.70 \\
\hline \multirow[t]{2}{*}{ Field } & 19 & 4.8 & 3.5 & 90 & 2 & 2.9 & 0.86 & 68.25 & 97.00 & 10.60 \\
\hline & 20 & 4.8 & 3.5 & 90 & 2 & 1.5 & 0.22 & 68.25 & 92.39 & 4.17 \\
\hline
\end{tabular}


A second series of experiments were run to test electron beam precharging at much higher particle concentration levels. Hydrated alumina (Hydral) dust having a resistivity of about $10^{13} \Omega$. $\mathrm{cm}$ was resuspended and injected into the EBP wind tunnel using a screw feeder/fluidized bed combination. These preliminary tests proved once again that E-beam precharging could reduce the overall particle penetration, although the $\alpha$-values were more modest at a figure of about 5 .

Electron beam precharging of fine particulate matter has been shown in these earlier studies to greatly improve the particle collection efficiency of a conventional electrostatic precipitator. Collection efficiency, according to the Deutsch-Anderson equation

$$
\eta=1-\exp \left(\frac{-A}{V} w\right)
$$

is dependent upon the collector plate $(A)$, the gas volume flowing through the precipitator (V), and the particle migration velocity $(w)$. For a given $A / V$, if the migration velocity in the collector can be increased, the collection efficiency should improve.

The theoretical migration velocity for field dependent charging is given as:

$$
w=\frac{2 \varepsilon_{0} E_{0} E_{\mathrm{p}} a}{\eta_{3}}
$$

where $w=$ collection efficiency, $\varepsilon_{o}=$ permittivity of free space, $E_{o}=$ charging electric field, $E_{\mathrm{p}}$ $=$ collecting electric field, $a=$ particle radius, and $\eta_{g}=$ gas viscosity. For a given particle radius and gas viscosity, the migration velocity varies with the charging and collecting electric fields $E_{o}$ and $E_{a}$, respectively). Setting aside the collecting electric field, if the charging electric field can be raised, the migration velocity and thus the collection efficiency should increase.

Even higher overall performance of the E-beam precharger/collector combination is expected with pulsed operation. Pulsing the precharger should result in higher particle charge since the saturation particle charge for field charging is dependent upon the electric field. Levels of DC electric 
field which would cause sparkover in the present Mk. III precharging configuration can be attained by using very short duration, fast rise time, high voltage pulses. In addition to higher electric field limits, other benefits which accrue with pulsed precharger operation include the avoidance of back corona, and the opportunity to take advantage of the copious supply of free electrons that are available from electron beam ionization of the test gas. Maximizing the particle collection efficiency of the EBP using high resistivity dust at moderate to high loadings will be the focus of the upcoming developmental work.

In an earlier study performed by the Aerosol Physics Group at FSU and sponsored by the U.S. DOE, positive pulsed streamer corona was used to promote the formation of free radicals $\left(\mathrm{HO}_{2}\right.$, $\mathrm{OH}$ ) in humid synthetic flue gas. These free radicals, in turn, reacted with the molecules $\mathrm{SO}_{2}$ and $\mathrm{NO}_{x}$, forming aerosols which could be removed by conventional means from the gas stream. Since $\mathrm{SO}_{3}$ and $\mathrm{NO}_{x}$ are the gas species principally responsible for the formation of acid rain, pulsed energized electron reactor (PEER) technology can be one component in reducing the emission of these harmful chemicals.

The power supply used in the pulse energized electron reactor experiments will be modified for use in the present pulsed electron beam precharger work. Instead of being used to produce streamer corona which initiates a series of chemical reactions in the PEER device, the pulsed power supply will be used here to provide a very high electric field for particle charging. The advantage in using a pulsed electric field instead of a DC field in the precharger lies in controlling the problem of back corona. When the precharger electrodes become coated with a layer of high resistivity dust, a voltage potential drop across the insulating dust layer occurs. This potential drop causes a breakdown in the dust layer, ejecting both dust particles and positive ions back into the flue gas stream. Pulsing the precharger electrodes reduces or eliminates this problem because the initiation of back corona is not possible within the time doms in of the very fast, high frequency, high electric field pulses. Work is now underway to ready the pulsed power supply for use with the electron 
beam particle precharger.

Section B of Technical Progress Report 1 contains a short description of the FSU Electron Beam Precipitator wind tunnel, as it is now configured. Section $\mathrm{C}$ describes the progress made on the stipulated contract tasks, namely, Task A - Precharger Modification, Task B - Charge-to-Radius System, Task C - Pulsed Power Stpply, and preparations for experimental Tasks D-H. Section D contains a reprint of a paper on the free electron charging of aerosol particles which appeared in print near the beginning of the contract period, and a short report on a paper presented at the DOE Flue Gas Cleanup Peer Review Meeting held in Maryland in late August, 1989. The project personnel are listed in Section $\mathrm{E}$. 


\section{CONCISE STATEMENT OF WORK PROPOSED}

Task A: Modification of precharger for pulsed and DC energization of anode.

Task B: Installation of the $\mathrm{q} / \mathrm{a}$ measurement system.

Task C: Modification and installation of pulsed power supply to provide both pulsed and DC energization of the precharger anode.

Task D: Measurement of the removal efficiency for monodisperse simulated fly ash particles for two energization frequencies and several pulse heights.

Task E: Measurement of particle charge for monodisperse particles for DC only and DC plus pulsed operation.

Task F: Optimization of pulse energization schedule for maximum removal efficiency of test aerosol particles.

Task G: Practical assessment of results for monodisperse test particles.

Task H: Measurement of the removal efficiency for polydisperse test particles for two energization frequencies and several pulse heights. 


\section{B. ELECTRON BEAM PRECIPITATOR TEST SYSTEM}

\section{Wind Tunnel Ductwork and Modules}

A review of the capabilities of the laboratory-scale Electron Beam Precipitator at FSU which was used to test the Mk. II and Mk. III E-beam precharger is presented in this subsection. The Electron Beam Precipitator (EBP) is basically an instrumented closed circuit wind tunnel composed of a number of specialized modules separated by ductwork sections (Figure 1). The specifications of the wind tunnel ductwork are as follows: Outside Dimensions $=20 \mathrm{ft}$ long by $8 \mathrm{ft}$ wide; Single Pass Length $=45 \mathrm{ft} ;$ Ductwork Size $=12$ in by 12 in $\left(1 \mathrm{ft}^{2}\right)$; Construction $=\# 30412$ gauge stainless steel; Gas Velocity Range $=3$ to $30 \mathrm{ft} / \mathrm{sec}$; Maximum Gas Flow Rate $=2000$ ACFM; System Pressure Drop = 5 inches Water Gauge. Specialized modules of the "racetrack" include the fan, an aerosol entrainment module, two monitoring modules, the precharger and collector composing the precipitator, and an absolute filter. The monitoring, aerosol entrainment, and precipitator modules each have removable plexiglass tops and opening ports on three sides for observing precipitator conditions and for the mounting of monitoring systems or aerosol injectors. EBP subsystems which are associated with the wind tunnel are several high voltage power supplies for the precipitator, gas condition, particle, and charge monitors, a microcornputer with data conditioning system, three aerosol generators, a closed-circuit TV system, and a humidity control device.

Circulating the gas and test aerosol through the wind tunnel is a stainless steel centrifugal fan rated at 2000 ACFM at 7 in. water gauge pressure drop. A variable opening outlet damper downstream from the blower controls the air velocity. To ensure a particle free gas flow for proper experimental control, a H.E.P.A.-type absolute filter is positioned upstream of the fan intake. One section just downstream from the fan outlet damper houses a humidity control device composed of a set of refrigerated coils and a compressor/condenser unit.

Aerosols of two basic types were resuspended in the aerosol entrainment module. The basic 


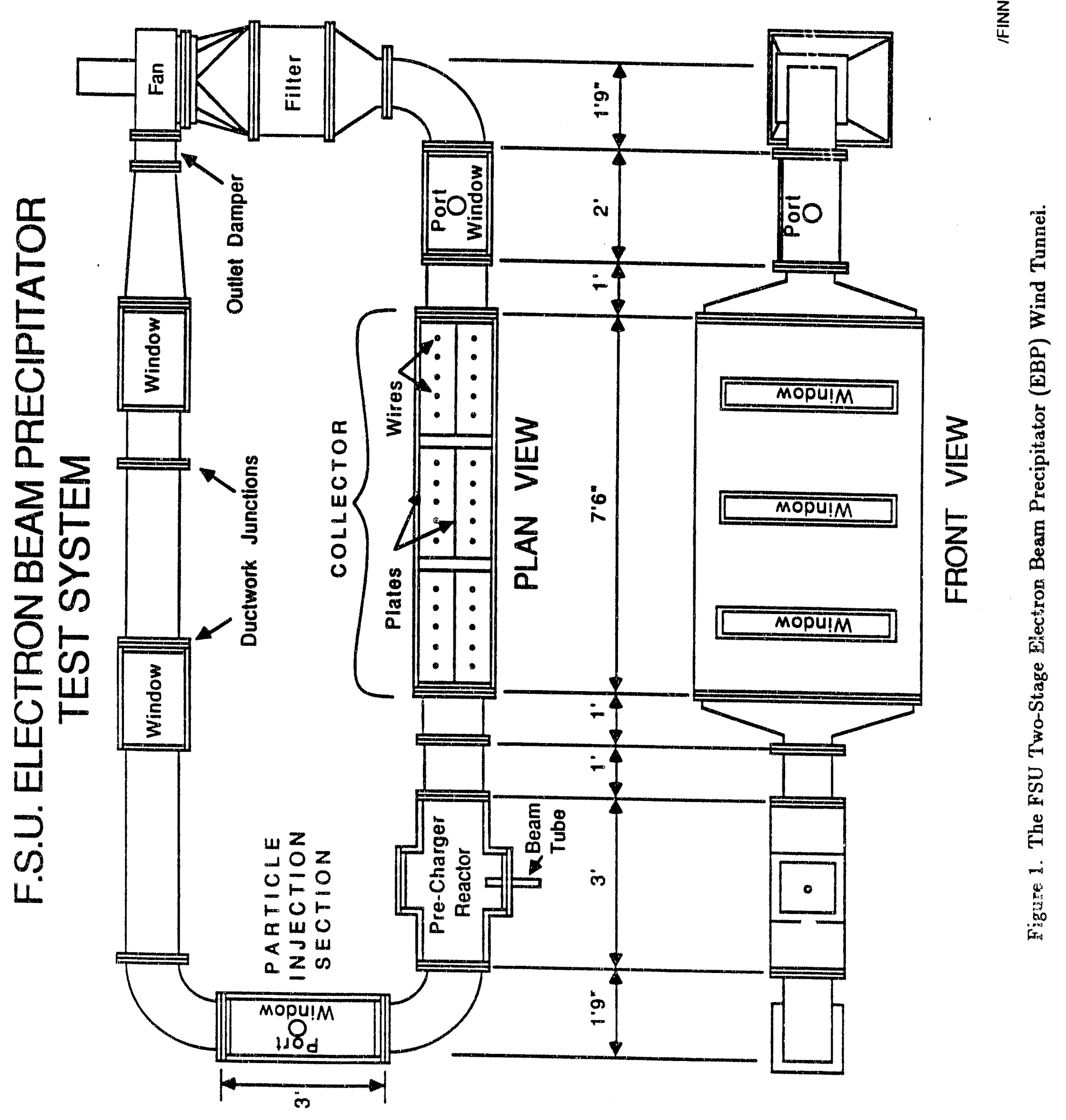


properties of electron beam precipitation (charying and collection efficiency, maximum field and current) were investigated using a monodisperse aerosol at low to medium loadings. High loadings of mono- or polydizperse bulk powders are needed to test the EBP under mcre realistic conditions. A Collison nebulizer-based fuid atomization aerosol generator entrains PSL (polystyrene latex par-: ticles) and a BGI Wright Dust Feeder, a rotating drum air injection bulk powder feeder, resurpends Hydral or fly an. For high loading applications using bulk powders, a fluidized bed fed by a large capacity screw feeder was employed.

Characterizing the operating conditions of the gas stream and the particie charging and collection efficiency of the EBP required a comprehensive group of monitoring systrms. These monitors must have remote controls and resdouts located in the E-beam control room since the EBP is in the accelerator target vault. Monitoring modules are located upstream and downstream from the precipitator for the purpose of before and after measurement of number of parameters.

Several monitoring systems measure gas stream conditions in the wind tunnel. A hot-wire type anemometer including a solid state temperature sensor is fasiened to a side port of the monitoring modules. Electronic ion exchange relative humitity/solid state platinum thermometer probes are fastened to plexiglass tops at two points: on the return leg of the EBP downstresm from the humidity control device and on the monitoring module adjacent to the collector.

'Two types of particle samplers monitor the EBP: real-time and time-integrated. Optical particle counters give a real-time indication of the number and size of particles present in a continuously sampled gas streami. A multi-stage cascade impactor and an absolute filter holder sample the gas How downstrearn from the collector in a time integrated fashion.

Particle charge versus mass measusement devices are used to quantify the effectiveness of the E-beam precharger prior to particle collection. A bulk charge-to-mass $(Q / M)$ sampler based on a Faraday Cagencased absolute filter can be used to measure total sample mass and total particle charge. A single particle charge-to-radiug (q/a) device developed at FSU was used to directly 
measure the mass and charge of individual particles. The device, described in detail elsewhere, operates by imposing an AC electric field on a chamber into which particles are intrcduced. A laser illuminates the ascillating particles, and a microscope lens and video camera display and record the event.

A microprocessor-based data acquisition and analysis system was developed to coordinate most of the data outputs of the Electron Beam Precipitator (Figure 2). It was used to accumulate, condition, process, and store all signals from the energized sections of the precharger and collector and from the EBP electronic monitors. Interfaced to the computer are a number of monitor signal inputs. These include: voltage and ion current signals from the precipitator through the $\mu$ Mac data conditioning system, the velocity and temperature sensors, and the optical particle counters and humidity/temperature probes through the multichannel analyzer. Data analysis subsequent to acquisition was performed using Basic and Fortran languages. In addition, a closed-circuit TV system was used to remotely monitor precharger and collector ion current meters on the high voltage side of the circuit.

\section{E-Beam Precharging Module}

Much of the recent work on FSP's has focused on precharging as a means of driving up the charge on particles to improve the efficiency for high resistivity tly ash. Electron beam precharging makes use of high ion current densities and electric fields to accomplish this goal. The FSU electron beam precharger is an in current separation and collection device for charging particles passing through the precharging module of the EBP. It provides a large electric field to ensure a high level of particle charge while allowing an unimpeded flow of particle-laden gas. High ion current dengity assures a rapid charging rate.

As described in earlier reports, a sub-duct or prosthesis was installed in the EEP racetrack to accept the prechargers transferred from the bench scale apparatus (Figure 3). The original 
MICROCOMPUTER DATA

ACQUISITION SYSTEM

CONTROL ROOM

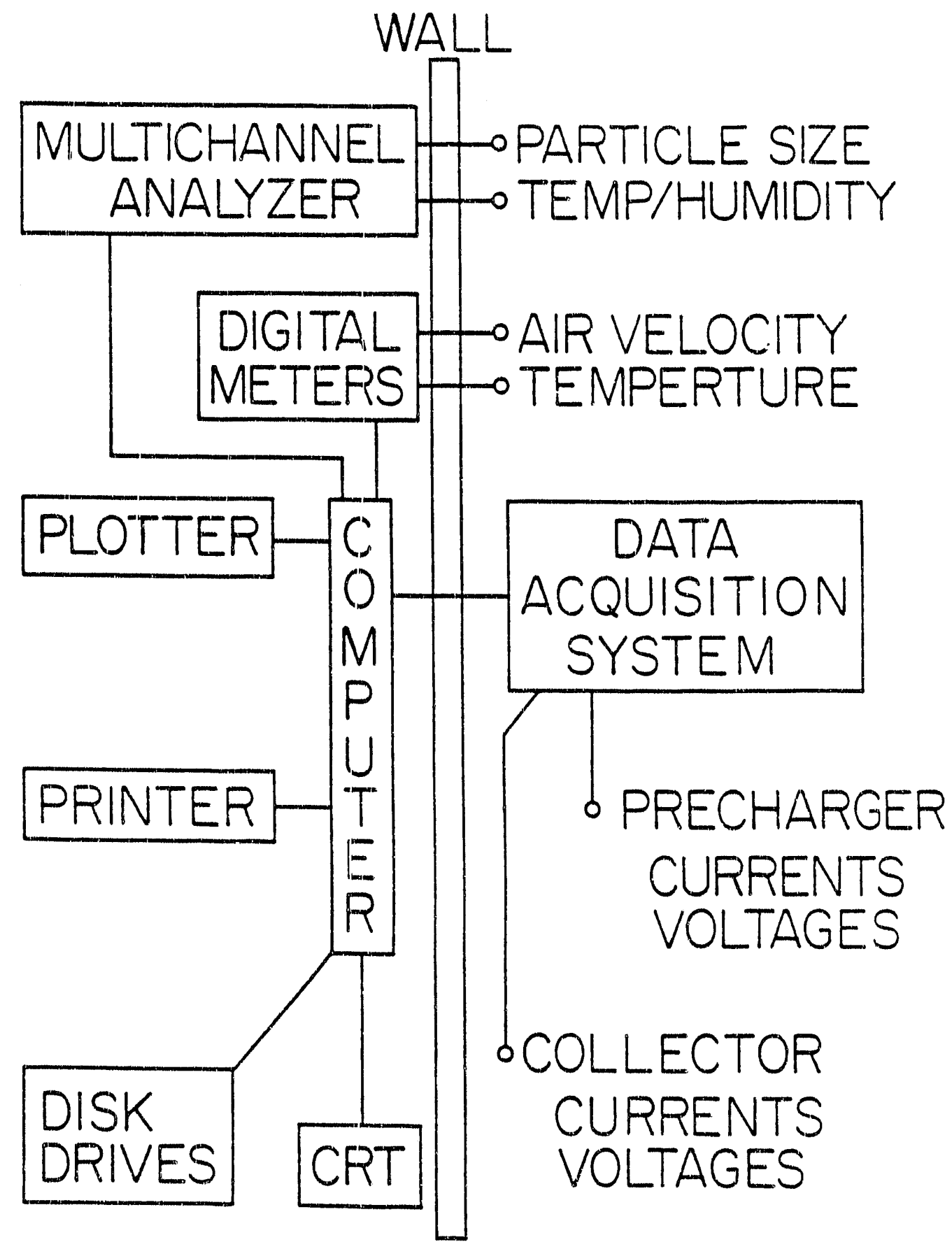

Figure 2. The Microprocessor-based Data Acquisition and Analysis System serving the Electron Beam Precipitator. 


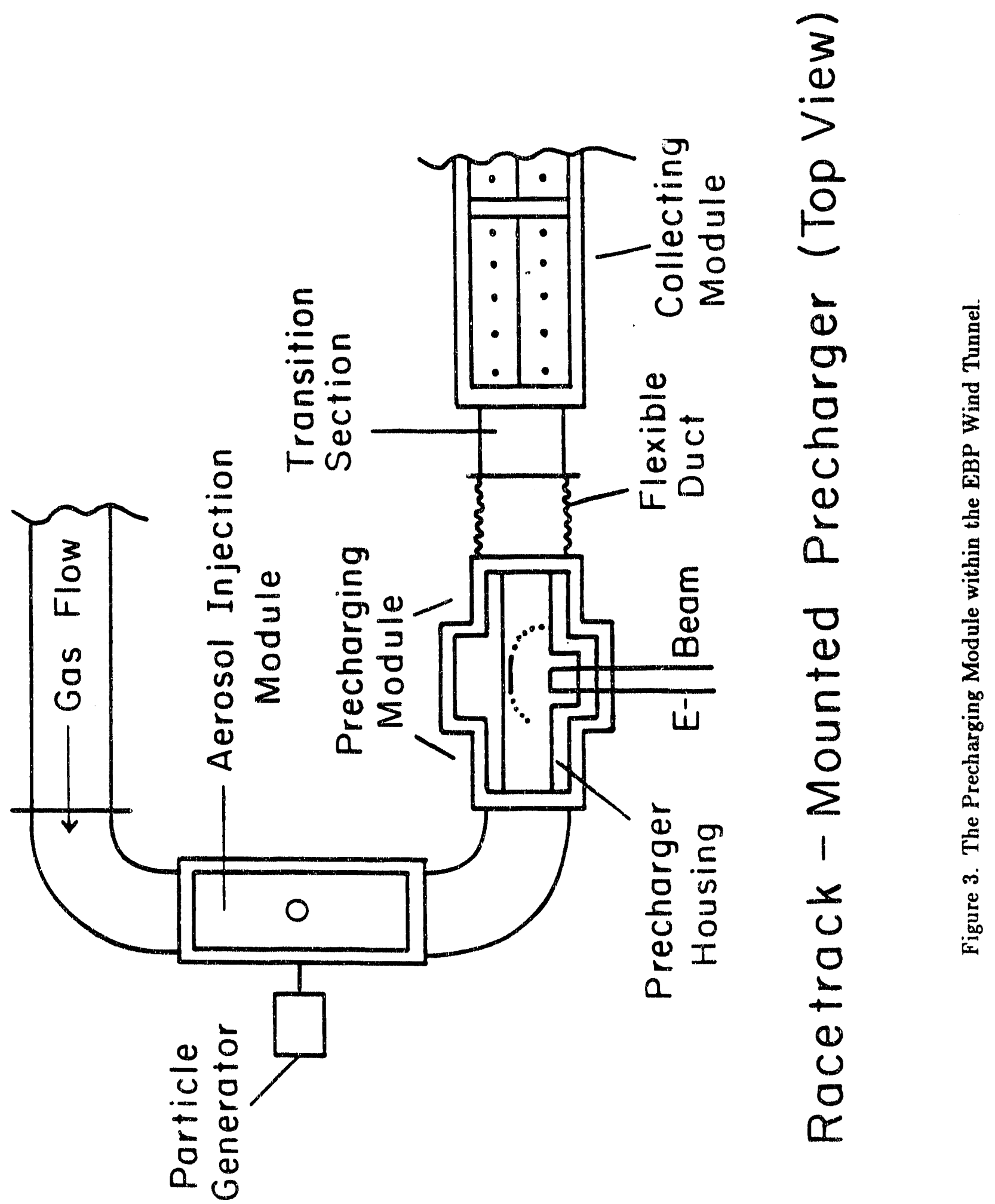


stainless steel precharging module was rotated $90^{\circ}$ and reattached to the system, allowing a $3 \mathrm{ft}$ long square PVC tube to be suspended in the center along the axis of flow. The cross section of the precharging module was reduced from 12 in. square to 6 in. square in order to satisfy the energy/geometry matching requirement for the laboratory constructed $100 \mathrm{keV}$ accelerator. While the low est energy from the Van de Graaff machine was too high for a 12 in. square precharger, a 6 in. square geometry provides an appropriate match to an energy of $100 \mathrm{keV}$. The ideal energy for a 12 in. square geometry is 200 to $400 \mathrm{keV}$ and future scale up will require the purchase of such an accelerator.

Velocity changes within the racetrack must be carefully documented since the critical regions are of different sizes. Cross-sectional areas for the critical modules are as follows: precharger sub-duct $=0.25 \mathrm{ft}^{2}$; wind tunnel ductwork, monitoring and aerosol entrainment modules $=1 \mathrm{ft}^{2}$; collecting module $=4 \mathrm{ft}^{2}$. Therefore, gas passing through the working precharging-collection region experiences a 16:4:1 reduction passing from precharger to $q /$ a monitoring section to collector.

\section{Accelerator, Vacuum Station, and Precharging Mechanics}

Ions and electrons for the particle charging process are provided by an electron beam source. The source itself is a $100 \mathrm{keV}$ maximum energy electron accelerator constructed at FSU, dubbed the MINACC. Within an evacuated, insulating PVC pipe are a hot filament cathode and a series of accelerating rings at successively lower electric potentials (Figure 4). The electron beam passes down the pipe and through a thin plastic film "window" out into the precharger where the ionization process occurs.

Maintaining the MINACC at a pressure level of approximately $1 \times 10^{-5}$ torr is a dedicated vacuum station, the BG-2 (Figure 5). Control over the pumping process is exercised by a CVC vacuum gauge controller and a series of solenoid-actuated valves. Protection for the diffusion pump is built into the station circuitry in case of an accelerator window blowout or nther major vacuum 


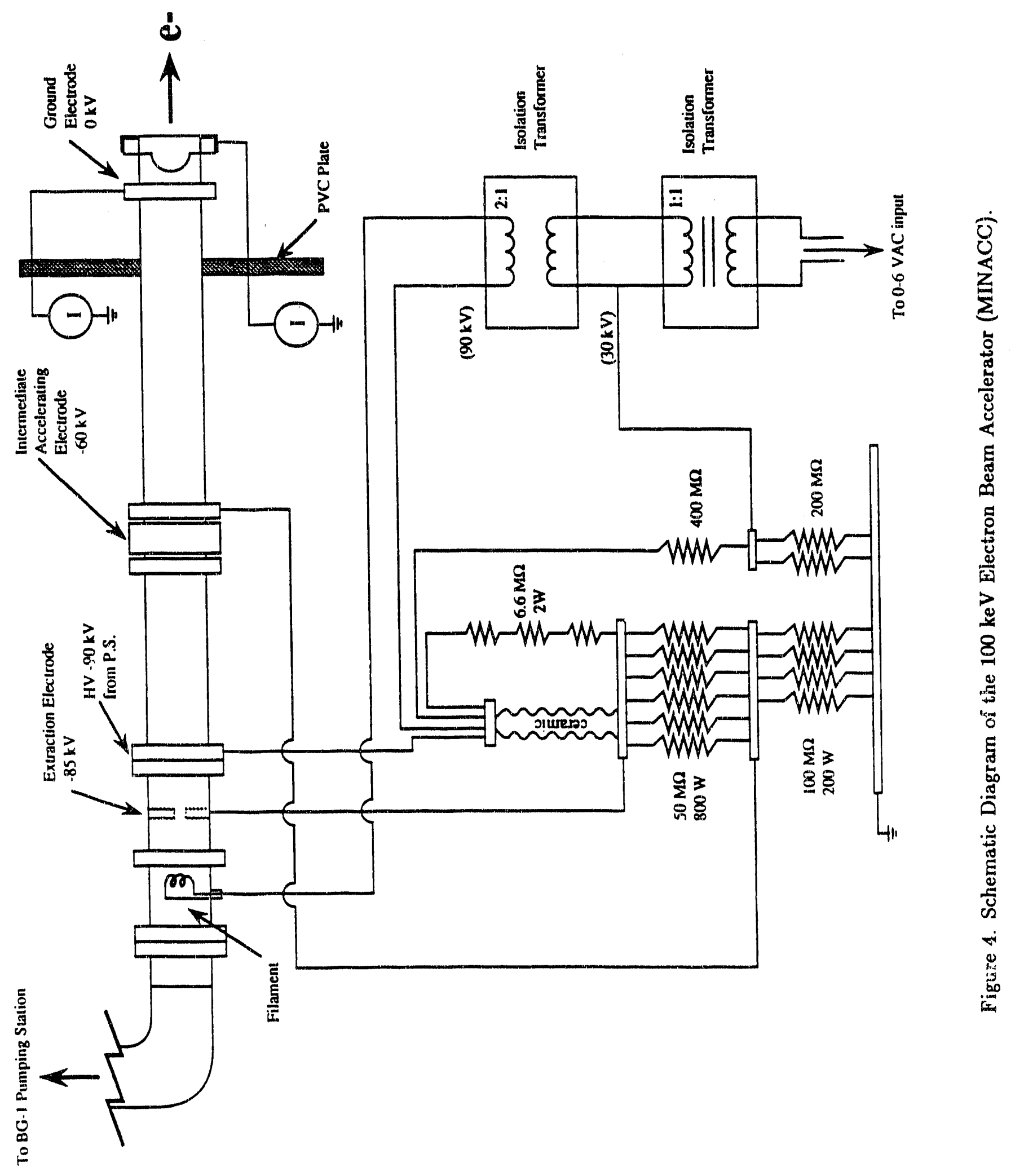




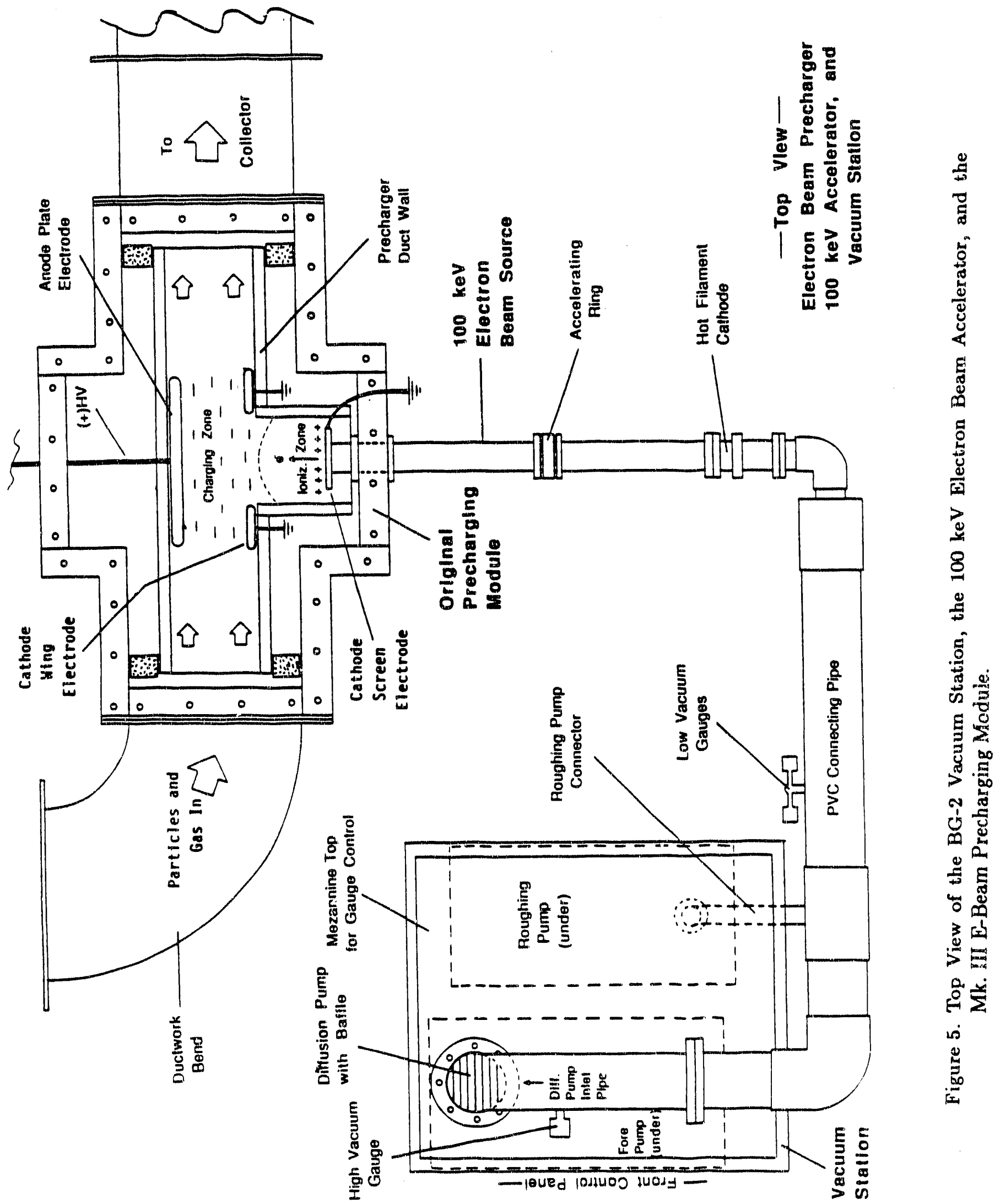


leak.

The mechanics of electron beam particle precharging have been described elsewhere in detail, but the process will be briefly outlined again. Figure 6 shows the present internal electrode configuration of the Mk. III E-beam precharger. As the high energy electron beam passes from vacuum into air through the "window" on the end of the MINACC, the ionization process comrnences. Positive and negative ions and serondary electrons are created at a rate dependent upon the initial electron beam energy and current. This zone of ionization is contained within a recessed area out of the flow of aerosol in the precharger.

Along both side walls of the inner precharging module are a set of plate electrodes which define the boundary of the charging zone (Figure 6). When an electric field is applied between the anode and cathode electrodes, the charge density is separated into two monopolar fractions. The negative fraction composed of ions and free electrons is drawn out into and maintained in the charging zone, through which particle-laden gas is flowing. High levels of particle charge and fast charging rates result from, respectively, the large electric fields and dense ion currents in the precharger.

\section{Collector Specifications}

The collecting section downstream from the precharger (Figure 7) is the other major component of a two-stage precipitator. For the FSU E-beam precipitator, the collector was designed to model a down-sized conventional electrostatic precipitator. It is a typical wire-plate configuration and it can be operated at relatively low voltage to give high particle collection efficiencies. The reason for using a wire-plate design is two-fold: 1 . to compare the collector operating at high current as an ESP with the collector operating at a low current used as a second stage for a precharger, and 2 . to realistically assess the performance of the E-beam precharger in a retrofit circumstance, i.e., upstream from a conventional wire-plate collector. A set of centrally located plates or large rods can replace the corona wires for investigation of a plate-plate collector if desired. Wide plate 

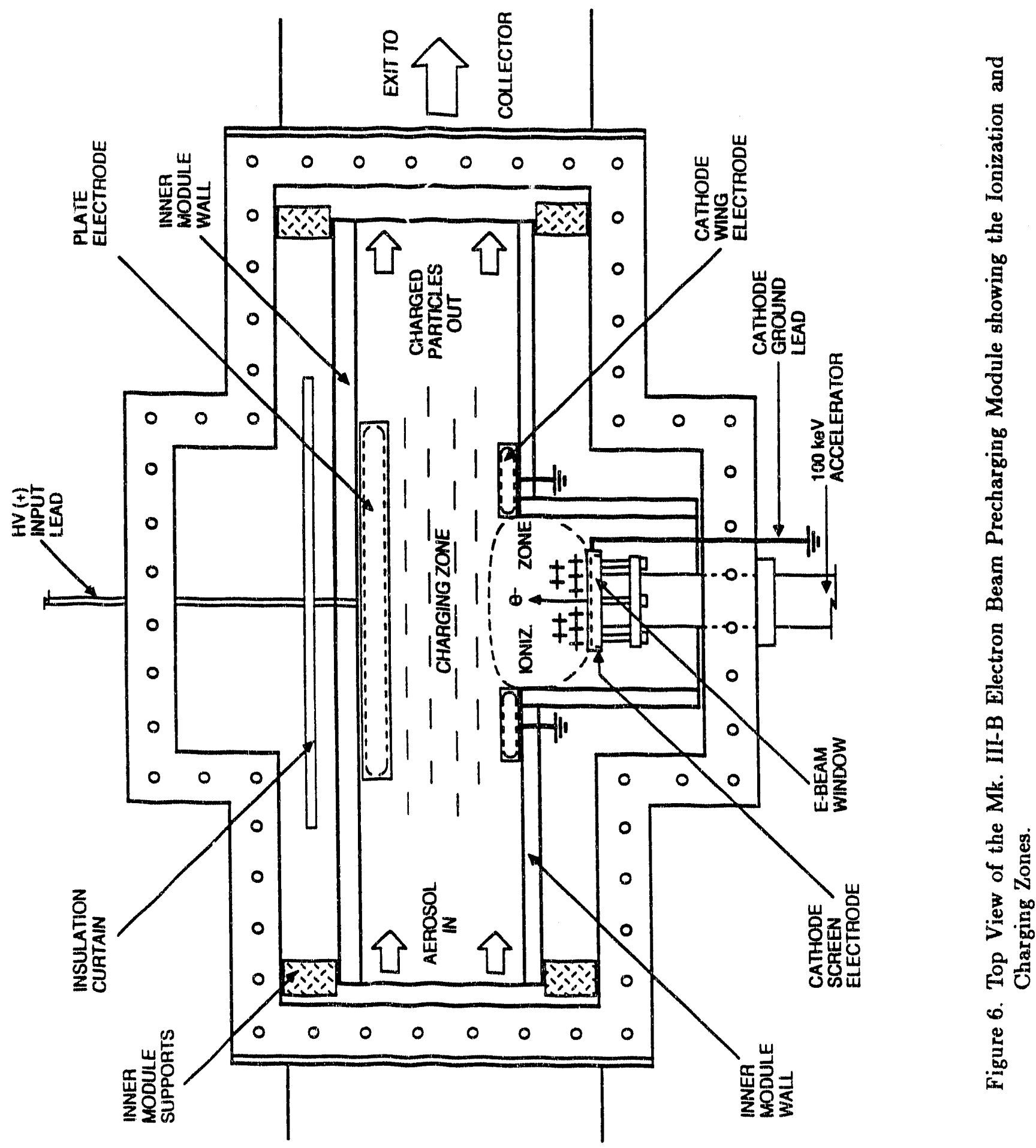


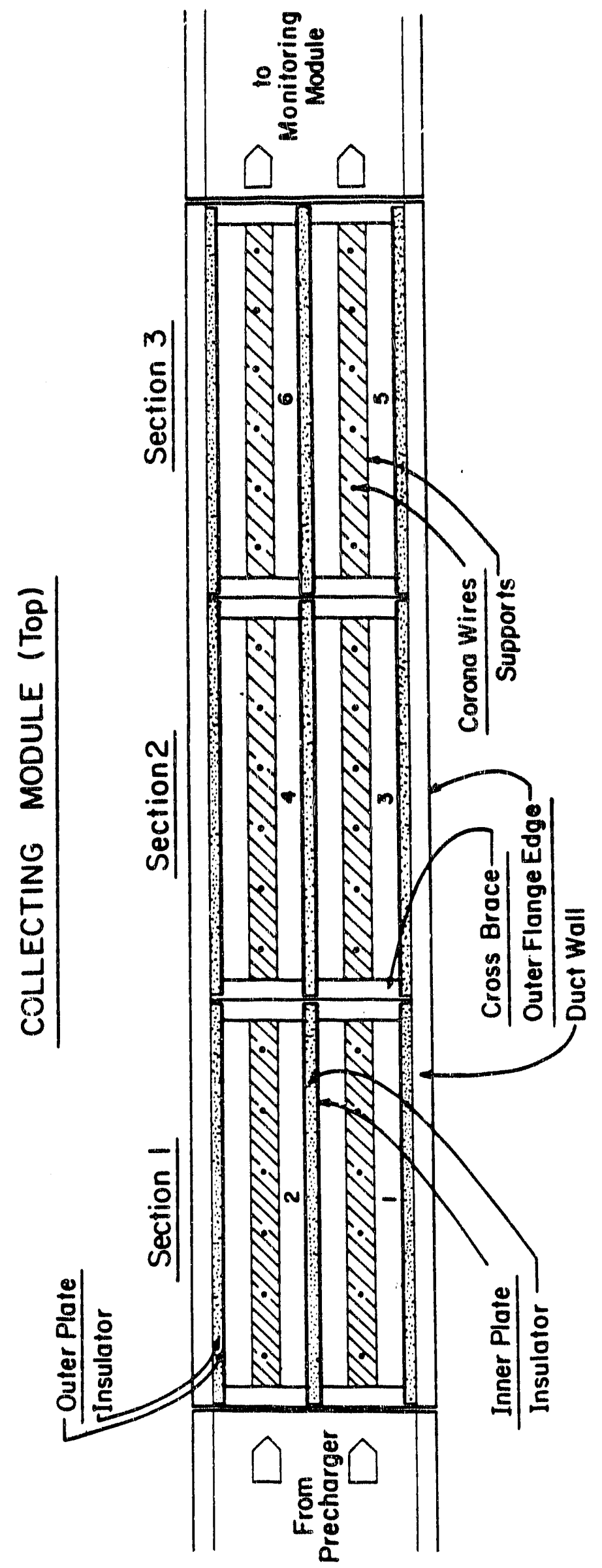

总 
spacing can also be studied by completely removing the center plates and all corona wires.

Gas entering the collector is split into two channels, each of which has three sections for a total of six fields (Figure 7). Plexiglass top and bottom covers seal the module. Twelve stainless steel coliector plates are mounted to standoff insulation and then to the collector frame. The six corona wire assemblies are each composed of six stainless steel corona wires suspended between aluminum buss rods which are insulated from the collector frame.

Corona wires of practically any diameter can be substituted for the present $1 / 10 \mathrm{in}$. diameter wires presently installed for testing. High voltage, high current DC power supplies are used to energize the collector. A $130 \mathrm{kV}, 30 \mathrm{~mA}$ unit provides voltage to the collector wires. The collector fields can be sectionalized if necessary using another $130 \mathrm{kV}$ supply.

Either of the two channels may be blocked off by a baffle plate, reducing the collection plate area by a factor of 2 and increasing the gas velocity in the open channel by a factor of 2 . Blocking one channel therefore results in an SCA reduction of 4 times. The specifications of the collection module and its internal components are as follows:

1. Collector Module Dimensions $=71 / 2 \mathrm{ft}$ long $\times 41 / 2 \mathrm{ft}$ high $\times 11 / 4 \mathrm{ft}$ wide.

2. Corona Wire Length $=48 \mathrm{in} .(122 \mathrm{~cm})$.

3. Corona Wire Diameter $=0.109$ in. $(2.8 \mathrm{~mm})$.

4. Wire-to-Plate Spacing $=3$ in. $(7.72 \mathrm{~cm})$.

5. Single Plate Dimensions $=4 \mathrm{ft}$ high by $2 \mathrm{ft} 6$ in. wide.

6. Total Plate Area $=120 \mathrm{ft}^{2}$.

7. Collector SCA $\left(\mathrm{ft}^{2}\right.$ per 1000 ACFM Gas Flow $)=200$ at a Collector Velocity $=2.5 \mathrm{ft} / \mathrm{sec}$. 


\section{Wind Tunnel Operating Characteristics}

The principle task completed during the contract previous to the one that this report addresses was the design and construction a laboratory-scale electrostatic precipitator which would be adaptable to a wide variety of experimental conditions. The EBP wind tunnel was subjected to a series of performance tests upon its completion. Among these tests were investigations of the air flow patterns through the system and a thorough examination of the racetrack electronic monitoring devices. These tests were generally successful although the monitoring systems, especially the Climet optical particle counters, were found to have larger errors than expected, which must be taken into account when using these devices for diagnostic purposes. The two Climet units always give somewhat different particle counts even when sampling the same gas stream, but initial difficulties obtaining quantitatively believable results have been overcome by internally adjusting the counring mechanisms.

The electron beam precipitator system represents a hostile environment in which to conduct experiments in two respects: jonizing radiation and high voltage energization. Shielding was provided to guard against radiation damage but the need to operate under frequent high voltage sparking conditions uncovered a serious earth-ground problem which deleteriously affected the EBP sensors and digital equipment. Electrical damage to electronic sensors and the data acquisition system was repaired, and several preliminary grounding configurations were tried with increasing success. The problem was partially solved by the installation of an extensive earth-ground network which effectively shunted the high voltage transients and prevented further instrument damage. 


\section{CONTRACT PROGRESS DURING QUARTER ONE}

\section{Task A - Precharger Modification.}

Previous equipment changes to the BG-2 vacuum station (Figure 5), dedicated to serving the $100 \mathrm{keV}$ accelerator required the addition of a larger diffusion pump. However, it was found that the power consumption of this pump was approaching the $\mathrm{AC}$ current limit of the existing 110 volt circuit in the laboratory area. In addition, some of the wiring within the station itself was becoming excessively hot under the load. The solution to this problem was the conversion of the entire system to 220 VAC operation. This change required the electrical reconfiguration of the mechanical pump motors, the diffusion pump heaters, and minor changes in the control circuitry. The final result of this change in the station power supply reduced the current drawn by roughly half and thus relieved the heating in the vacuum station and associated wiring.

2. Task B - Installation of the Charge-vs.-Radius Apparatus.

The beginning of this contract period was spent removing the single particle charge vs. radius (Q/A) measurement system (Figure 8) from the Free Electron Charging Experimental Apparatus used in the previous contract and preparing it for its new role. The $Q / A$ device will be used to measure the charge and size of particles sampled from the electron beam precharger, as stipulated by the current contract tasks. This new application of the $Q / A$ system required a number of modifications, which consisted of the redesign of the gas flow system into and out of the measurement cell to allow connection to the wind tunnel and those changes necessary to operate the unit remotely so as to satisfy radiation safety requirements. Modifications for rernote operation included the lengthening of the video, solenoid valve, pump, and power cables, and the mounting of a remotely controlled low speed motor to the focus control of the Q/A optical subsystem. This motor allows 


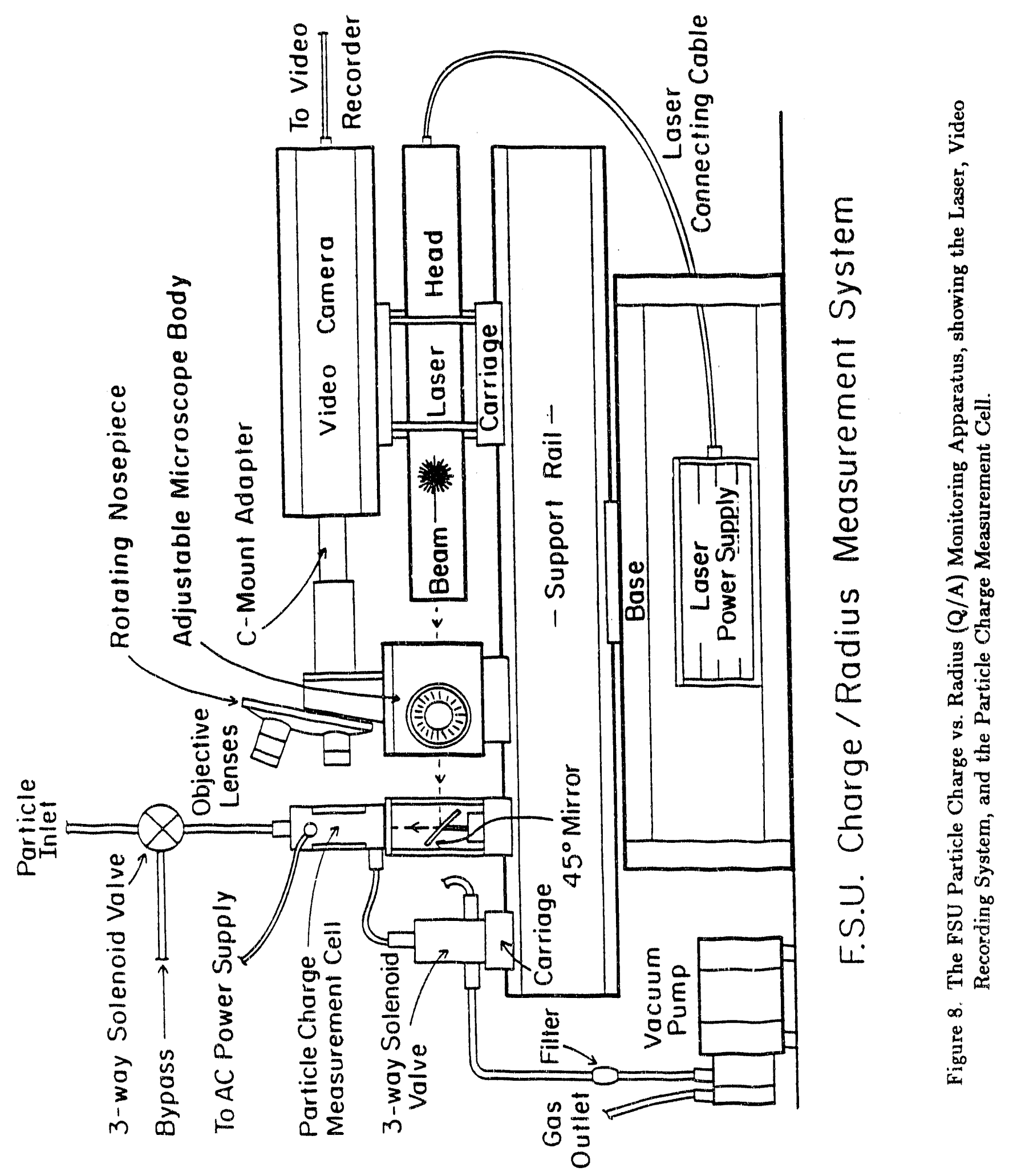


the operator (who is in a different location from the Q/A apparatus) to "chase" desired particles as they change viewing depth within the $Q / A$ measurement cell.

Once the $Q / A$ system was successfully connected to the racetrack downstream from the precharger, several high loading runs using Hydral and fly ash test dust were completed. Both collection efficiencies and particle charge of selected samples were messured and recorded for different precharger conditions. The raw particle charge and radius data was recorded on videotape for later analysis.

Though good data was obtained using the modified $Q / A$ system in its new role, some deficiencies were noted. The most troublesome was the slow buildup of an opaque particle film on the observation wndow of the measurement cell. This film obscured the suspended particles in the cell from view, eventually making charge and fall-rate measurements impossible and forcing an end to such measurements until the cell could be diassembled and cleaned. This problem is almost certainly due to the extremely high concentration of particles produced for the high loading experiment.

The remainder of the first crntract period was spent analyzing the data collected, calculating theoretical values for the experimental conditions, and preparing publication quality graphs. The availability of Macintorh computers and laser printers through the Uriversity's Microcomputer Center has allowed the production of high quality graphs of the charge vs. radius data obtained for use in technical reports and publications. The raw dala is first measured from the videotaped behavior of particles under known conditions and then entered into a computer spreadsheet where the charge and radius are calculated. The Macintosh version of Microsoft Excel was used for the calculations. The resulting table of particle charges and radii is then transferred to CricketGraph, a graphing software package, and used to produce graphs of particle charge versus particle radius. The graphs were then transferred to MacDraw II for final editing and printing.

A complete description of the FSU laser-oscillating field charge v8. radius measurement system 
will appear in Technical Progress Report No. 2.

3. Task $\mathbf{C}$ - Modification and Installation of Pulsed Power Supply.

The main objective of this contract is to test the particle collection efficiency of the existing precharger and precipitator system with a pulsed rather than a DC voltage applied to the precharger. One of the first steps taken toward the initiation of this work was the modification of the existing precharger setup so that it can be driven not only by its existing DC power supply, but by a pulsed power supply as well.

To install the pulsed power supply, a $3 \times 4$ foot platform was constructed in the middle of the precipitator test loop. This location was chosen because of its close proximity to the precharger, its safety, and its convenience. The platform was braced by adding iron cross-members to the structure across one end of the wind tunnel. These new cross-members support a table top of $1 / 2$ inch thick plywood covered with $3 / 8$ inch thick PVC sheet as an insulator.

The pulsed power supply installed on this platform was transferred from the previously described PEER project. This supply, designed and assembled at FSU (Figure 9), can produce pulses of approximately $80 \mathrm{kV}$ amplitude, $20 \mathrm{~ns}$ rise time, and variable duration at either 120 or 60 cycles per second. It consists of a current limiting resistor, high voltage rectifier network, high- voltage capacitor bank, rotating spark-gap, and a duration limiting resistor which is housed in a cooling tower (Figure 10). This power supply, with minor modifications, was used to drive the pulsed streamer corona reactor for the removal of $\mathrm{SO}_{2}$ and $\mathrm{NO}_{x}$, where it has performed quite well in the past.

After the pulsed power supply was completed and installed, a coupling capacitor bank and current limiting resistor were mounted on the outside of the precharger near the pulsed power supply. These two devices were added to isolate the high voltage DC input from the pulsed power supply, and vice-versa, when both are driving the precharger together. This configuration is nec- 

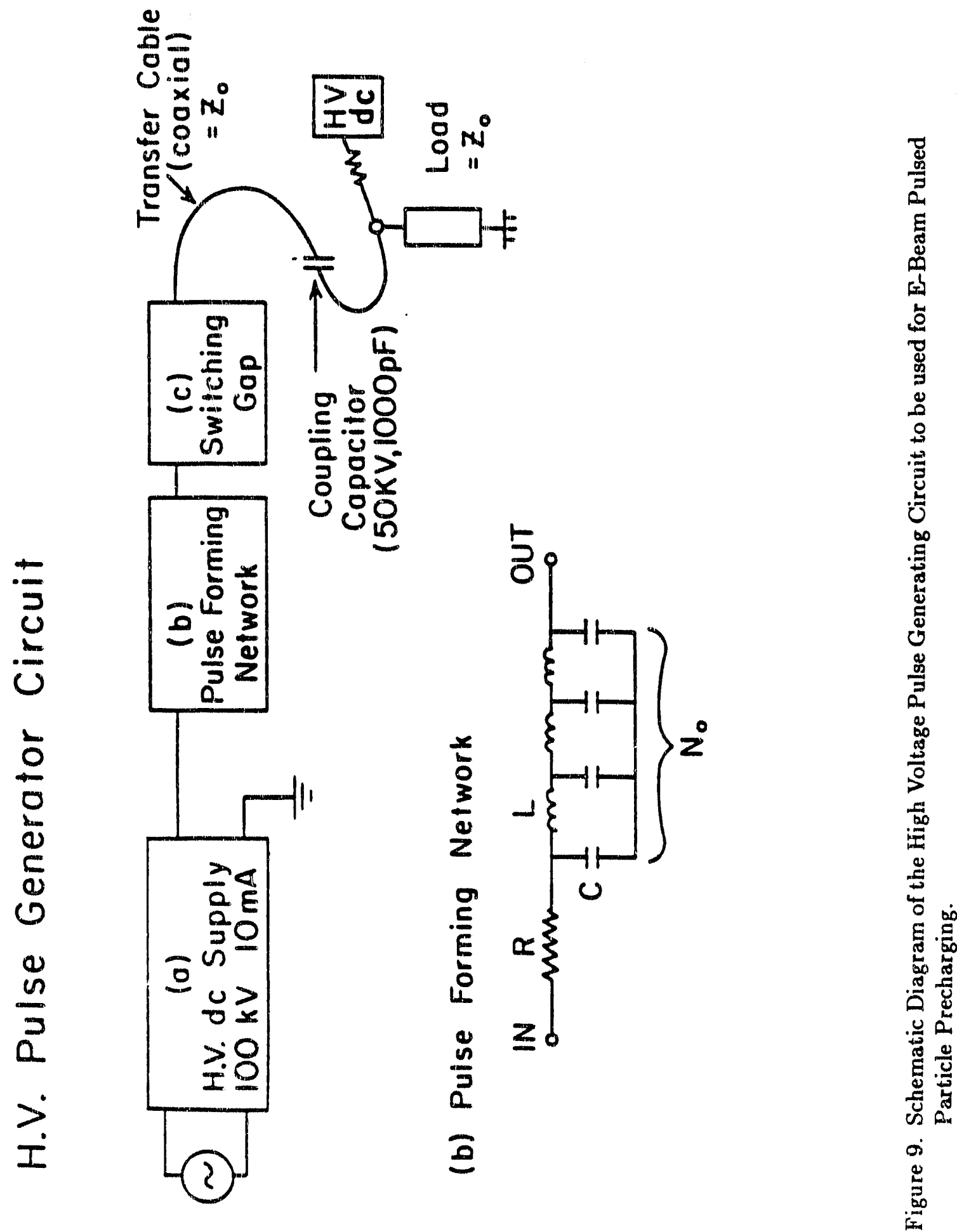


\section{High Voltage Power Supply}

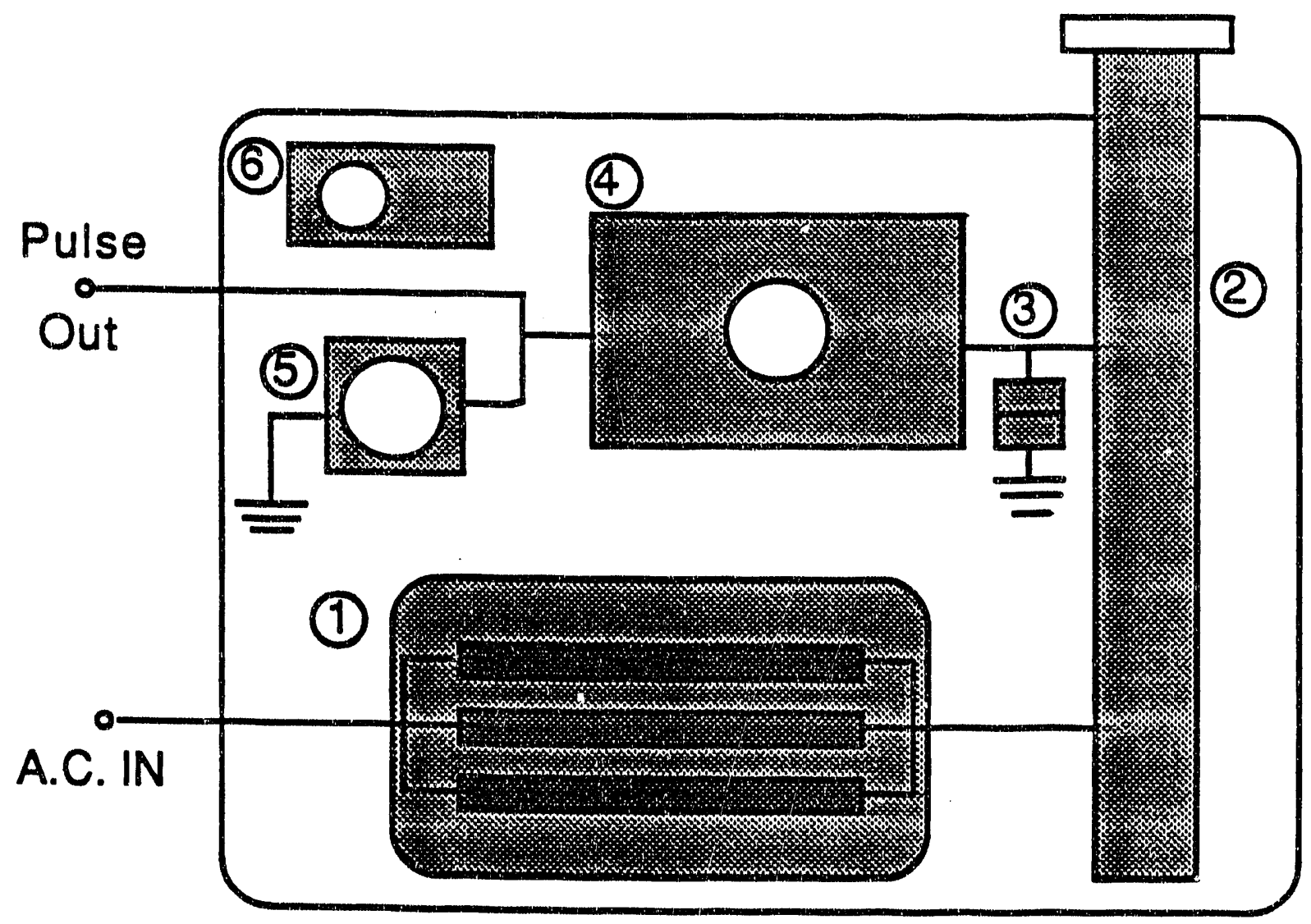

Figure 10. Top View of the High Voltage Pulsed Power Supply showing the Rectifier Network, the Capacitor Bank, and the Rotating Spark Gap.

1. High Voltage, Current Limiting Resistor Network $(333 \mathrm{k} \Omega)$ in Oil Bath.

2. High Voltage Rectifier Cooling Tunnel.

3. Capacitor Bank for pulse forming.

4. Mechanical Spark Gap, $1800 \mathrm{rpm}$, spark frequency $=60 \mathrm{~Hz}$.

5. "Tail" Resistor Cooling Tower.

6. Strobe Lamp for Spark Gap Synchronization. 
essary in order desired to produce a pulsed voltage with a DC bias at the anode of the precharger. Specifically, the coupling capacitor bank will serve to isolate the "tail" resistor of the pulsed power supply from the large DC offset or bias voltage, while the current limiting resistor will protect the DC power supply in the event of a short at the precharger and will also isolate it to some degree from the pulsed produced by the pulsed power supply (see Figure PS- 3 for a schematic of this system). These changes will allow the precharger to be driven by essentially three different voltage waveforms, those being 1) DC 2) pulsed 3) pulsed with DC bias.

To measure the current and voltage supplied to the precharger by the combined power supplies, a high speed digitizing oscilloscope must be acquired which has both waveform-time-averaging and trigger delay abilities. These oscilloscope features are necessary because the high voltage pulses produced by the pulsed power supply are both extremely fast and not uniform in amplitude, thus making them very difficult to measure with more conventional models. When the DC power supply is used alone, a good analog ammeter will be installed in-line between the DC power supply and the current limiting resistor.

4. Tasks D - H - Preparations for Experiments.

a. High concentration aerosol generation

As was reported in the Final Report to the U.S. Department of Energy for DOE Contract Number DE-AC22-86PC91021 (May 6, 1986 - March 5, 1989), there were several problems encountered with the original high concentration aerosol generation system (Figure 11) used to supply test dust to the EBP wind tunnel. In these earlier experiments, the monodisperse Hydral dust, which is norninally $1 \mu \mathrm{m}$ in diameter, was measured with a Climet optical particle counter to be as much as $2.5 \mu \mathrm{m}$ in diameter. This discrepancy was attributed to the incomplete de-agglomeration of the raw Hydral dust in the fluidized bed, caused in part by a large accumulation of dust in the bed ma. 


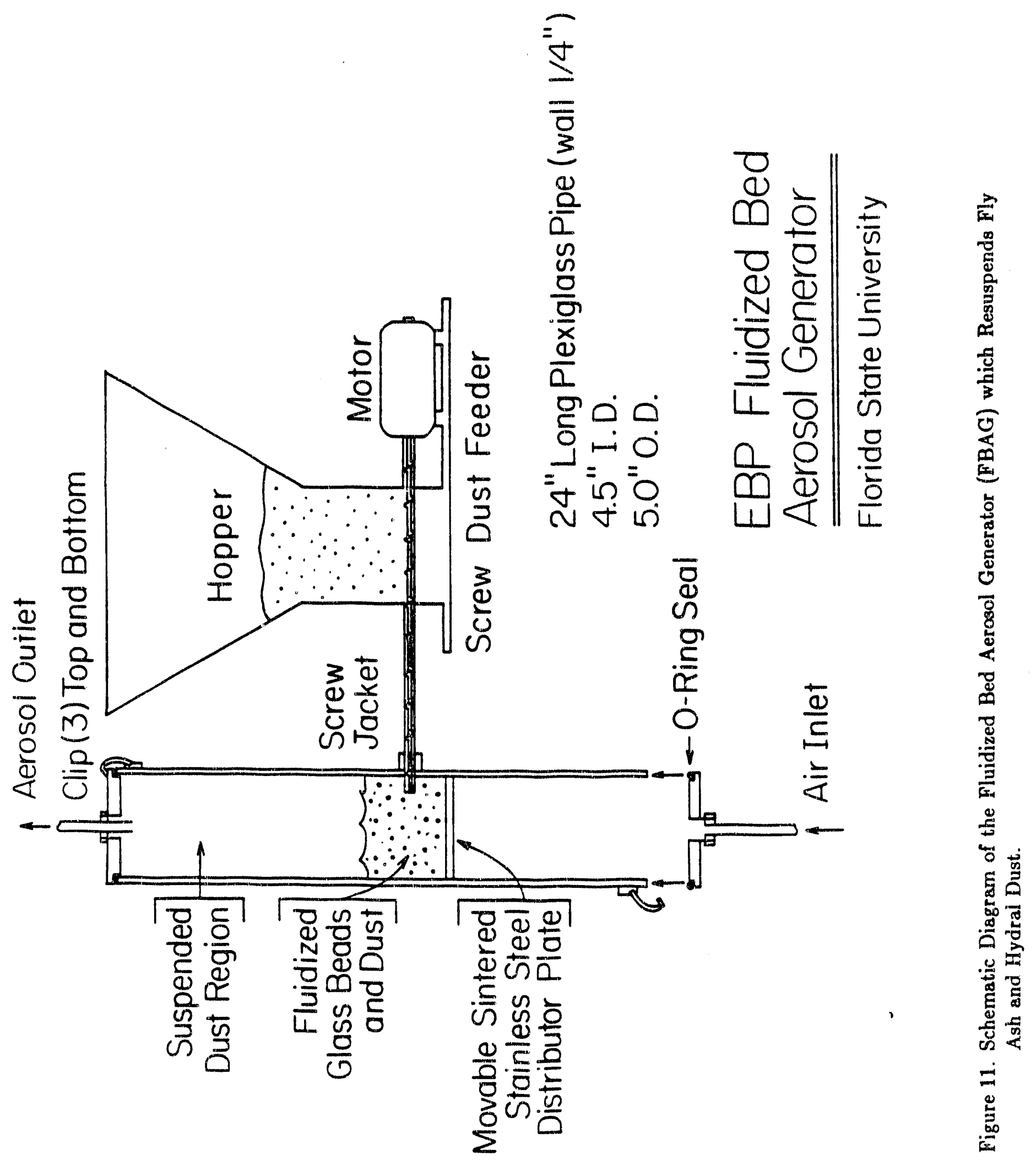


terial. A study was performed to determine the most effective way to correct this deficiency, which resulted in the conclusion that the sintered gas distribution plate and the semi-porous rigid screen needed to be modified and enlarged to allow a larger volume of gas flow at a lower pressure to pass. This remedy should maintain the integrity of the gas supply in the closed system while reducing the gas velocity through the bed material. A determination of the limits of the fluidized bed with regard to the volume of gas flow and the dimensions of the bed material and gas distribution plate was also needed. The center disk was set into a 5 inch diameter plexiglass cylinder.

Work was begun to redesign the sintered gas distribution plate and the semi-porous rigid screen. The sintered gas distribution plate was the first item to be considered. Previous models had clogged with dust, obstructing the gas flow. This caused the dust and bed material to settle around the sides of the tube allowing a saturation condition to commence. It was assumed that sloping the edges of the sintered gas distribution plate toward the center would allow the material to be transported back towards the middle active portion of the bed, compensating for this undesirable state. A sloping surface gas distribution plate was fabricated and installed into the plexiglass tube with better results.

Figure 11 illustrates the original Guidized bed setup. Hydrated alumina (Hydral) dust was used to simulate high resistivity fly ash in the setup. The Hydral was fed by an AccuRate screw feeder into the bed material consisting of glass beads of 425 to $600 \mu \mathrm{m}$ in diameter which broke up most of the clumps of hydral. A very fine dust was produced at the output of the fluidized bed. The major problem with this design was that hydral would still collect on the outside ledge of the gas distribution plate.

The next question was how best to attach the semi-porous rigid screen to the sintered gas distribution plate in order to avoid the collection of dust around the edge. It was decided to design another plate that would permit a screen to be attached to the surface of the plate rather than to the fistorn of the plate. The screen was attached to the plate using a metal circular hollow disk 
that was screwed on to the plate surface. When this plate was tried out, the air pressure required to significantly agitate the glass beads was approximately 40 PSI. This resulted in much too great an air flow through the cylinder, and because of the slight agitation of the beads, the hydral tended to clump together and remain of the surface of the top of the plate.

The main concern was to reduce the amount of pressure and at the same time achieve a greater agitation of the glass beads. For this reason a revised gas distribution plate and a new cylinder with a smaller diameter were constructed, thereby decreasing the required pressure and increasing the agitation of the glass beads. A new gas distribution plate was designed in which a screen was sandwiched between two disk halves fabricated out of PVC. The top disk had a sloping edge as in an earlier model. The surface, however, was much smoother and steeper than that of the first sloped disk and was found to operate more efficiently than any of the previous designs.

In the past, the screens had been very rigid and stable, however, since future screens were being chosen for their ability to allow a greater volume of gas to pass, while also preventing the dust and bed material too, this now became a prime consideration. One solution was to design an apparatus to stretch the screen evenly in order to prevent any buckling, thus creating a fiat even surface. The screen was then glued into place between two PVC disks; this assembly became the new gas distribution plate. The cylinder surrounding the gas distribution plate was also redesigned. A 3.0 inch inside diameter plexiglass cylinder was used in place of the original 5 inch cylinder.

A report on this latest version of the fluidized bed dust feeder will be detailed on in Technical Progress Report No. 2. 
D. PUBLICATIONS, PRESENTATIONS, AND PARTICIPATIONS

\section{Free Electron Charging of Aerosol Particles}

The paper reprinted in this section, entitled "Aerosol Particle Charging by Free Electrons", and authored by D.B. O'Hara, J.S. Clements, W.C. Finney, and R.H. Davis, all then of the Aerosol Physics Group, was published during the contract lapse period of March - August, 1989. It appeared in print in the Journal of Aerosol Science, Volume 20, Number 3, pp. $313-330,1989$. Because of its importance as a stand-alone work and its relevance to the ongoing development of the pulsed electron beam precharger, the article is reprinted in its entirety here. 
2. Flue Gas Cleanup Peer Review Meeting - Bethesda, MD

The Office of Program Analysis, located within the Office of Energy Research (ER) of the U.S. Department of Energy recently conducted an assessment of the research projects in the Fossil Energy Flue Gas Cleanup Program. The review of Flue Gas Cleanup projects occurred during a workshop held at the Hyatt Regency Hotel, Bethesda, MD, on August 22-24, 1989. Prof. R.H. Davis, Principal Investigator of the U.S. DOE contract entitled "Flue Gas Cleanup Technology Utilizing Energetic Electrons" presented a summary of the project results and outlook to a peer review panel. A Project Output Statement and other relevant information concerning the work of the Aerosol Physics Group at FSU was also submitted to the reviewers. 
E. PERSONNEL

Scientific Investigators

1. Dr. Robert H. Davis Principal Investigator

2. Mr. Wright C. Finney Associate in Research

Graduate Student Assistants

1. TBA

Undergraduate Student Assistants

1. David Eibeck

2. Arnnie Gibson

3. Chris Oswald

4. Misho Sarwar

Part-time Secretary

1. Natalie Duguid 

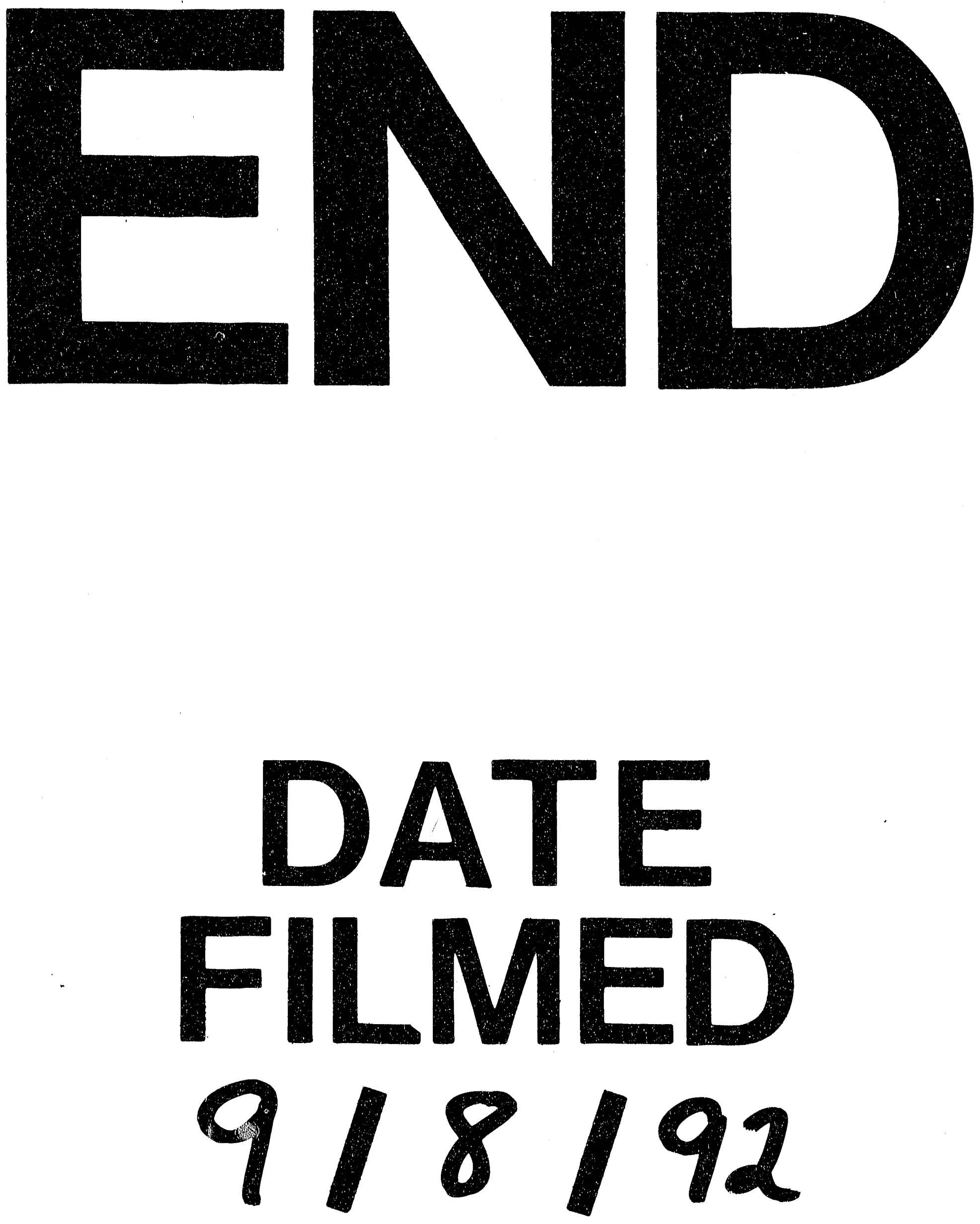
